REVISTA DE DERECHO UNED, NÚM. 11, 2012

\title{
APROXIMACIÓN AL CEREMONIAL Y PROTOCOLO \\ EN LOS VIRREINATOS AMERICANOS: EL RECIBIMIENTO VIRREINAL
}

\begin{abstract}
APROACH TO THE CEREMONIAL AND PROTOCOL IN THE AMERICAN VICEROYALTIES: THE VICEREGAL RECEPTION
\end{abstract}

Manuel Casado Trigo

Investigador, Departamento de Historia del Derecho, UNED ${ }^{1}$

Universidad de Sevilla

Resumen: A finales del siglo XVI se exporta a los territorios conquistados un modelo cortesano inicialmente idéntico al castellano, si bien mediatizado por los condicionantes demográficos de una población indígena, un territorio abrupto y un entorno sustancialmente distinto al de los territorios peninsulares. La ceremonia limeña, imitando la severa etiqueta de la Corte madrileña, se caracterizará, por un lado, por ser reflejo del ordenamiento social, al establecer una jerarquía estricta entre los individuos marcada por su cercanía al virrey, acentuando de ese modo su posición social, y, por otro, por ser un sistema que persigue realzar la sacralidad de la figura mayestática e inaccesible del virrey.

Palabras clave: Virrey, Ceremonial, Recibimiento, Perú, Etiqueta, Corte.

Abstract: In the late sixteenth century a model court initially identical to the Castilian court is exported to the conquered territories, although mediated by demographic factors of an indigenous popula-

${ }^{1}$ Doctorando del programa de doctorado «Fundamentos históricos de la Edad Moderna» del Departamento de Historia del Derecho y de las Instituciones. Directora: María Dolores del Mar Sánchez González. 
tion, a rough territory and an environment substantially different from that of the peninsular territories. The Lima ceremony, thus mimicking the strict etiquette of the Court of Madrid is characterized, first for being a reflection of the social order, establishing a strict hierarchy among individuals marked by its closeness to the viceroy, thereby accentuating their social position, and second as a system that aims to enhance the sacredness of the majestic and unapproachable figure of the viceroy.

Keywords: Viceroy, Ceremonial Reception, Peru, Tag, Court.

Recepción original: 06/08/2012

Aceptación original: 09/08/2012

Sumario: I. Antecedentes; II. La institución virreinal: El virrey; III. El recibimiento de los virreyes; IV. Conclusiones.

\section{ANTECEDENTES}

Los virreinatos peninsulares fueron los primeros en ser creados, seguidos por los italianos (dependientes de Aragón), y finalmente por los americanos de la Nueva España (1535) y del Perú (1542). Aparte del factor temporal, existían también otras diferencias entre unos y otros. La primera es, sin duda, la distancia que separaba los reinos americanos de la metrópoli; la segunda diferencia consistirá en que los americanos eran inmensos, sin límites fijos y con fronteras pobladas de indígenas, y por último, la diversidad étnica americana implicaba gran complejidad cultural. Como un aspecto no menos importante para comprender la organización política del Nuevo Mundo hay que considerar el papel de la Iglesia católica. Esa alianza del trono y el altar obedecía a que, durante la Edad Media, la civilización europea estimaba inseparables el orden sobrenatural, el natural y el de las leyes debido a la concepción teocéntrica del mundo ${ }^{2}$ y de la sociedad. Los fines religiosos del Estado se incrementaron notablemente en América al asumir la Corona las enormes tareas de evangelizar a la población indígena y organizar la implantación de la Iglesia, además de protegerla y defenderla. El interés era recíproco: la Iglesia recibió del Estado financiación generosa, y el Estado de la Iglesia apoyo político y legitimación ética, jurídica y religiosa.

2 CÉspedes del Castillo, G., "La organización institucional», en castillero calvo, a. (dir), Consolidación del orden colonial, Historia General de América Latina, Vol. III., Ed. Trotta., págs. 29 ss. 


\section{LA INSTITUCIÓN VIRREINAL: EL VIRREY}

En la Lima del siglo XVII se asentó una Corte en torno a los virreyes que, a pequeña escala, copió el modelo de la castellana de la dinastía de los Austrias ${ }^{3}$.

La corte de Isabel y Fernando se caracterizó, en lo ceremonial y el protocolo, por la ausencia de Corte, dado el carácter trashumante de unos soberanos en guerra continua y una movilidad permanente, por lo que se debe acudir a la implantación del nuevo orden proveniente de Europa que Carlos I promueve para la casa de su hijo, hecho que se plasma el día 15 de agosto de 1548 cuando se comenzó a servir a don Felipe a la borgoñona ${ }^{4}$. Hasta el reinado de este (1556-1598) no nace el denominado por Domínguez Casas «protocolo español».

Un rasgo fundamental de la Corte sería la jerarquía estricta entre los individuos, aunque lo que realmente definiría al cortesano sería la posibilidad de acceso directo al gobernante. La etiqueta no era sino una representación del orden social en la que los individuos salvaguardaban sus preeminencias y afianzaban su prestigio.

El siglo XVII fue el del apogeo del poder virreinal. Los gobernantes se sintieron verdaderos representantes del rey, su «alter ego». No obstante, al proceder de segundones de familias castellanas de la alta nobleza y ser nombrados por un tiempo, dependían del sueldo que la Corona les otorgaba, de modo que, a pesar del aura que los rodeaba, no eran más que meros funcionarios al servicio del monarca.

En realidad, la situación de los virreyes americanos era muy ambigua. Sus atribuciones y prerrogativas distaban mucho de estar claramente definidas. Los soberanos siempre mantuvieron ambigüedades en las funciones con el fin de conservar un margen de acción y de reservarse en última instancia el papel de árbitro. Como consecuencia de esa indefinición, los virreyes se vieron frecuentemente envueltos en conflictos endémicos con instituciones como las audiencias, los cabildos y la Iglesia.

3 Torres Arancivia, E., Corte de virreyes. El entorno del poder en el Perú del siglo XVII, Fondo Editorial PUCP, 2006.

${ }^{4}$ Otero Alvarado, María Teresa, Teoría y estructura del Ceremonial y Protocolo, Mergablum, Edición y comunicación, S.L., 2000, págs. 68 ss. 


\section{II.1. Los personajes del entorno virreinal}

La Corte virreinal peruana estaba conformada por dos sectores claramente diferenciados: la casa del virrey y la cancillería, es decir, los burócratas y administradores del reino.

Por casa del virrey debía entenderse el ámbito privado del gobernante, parientes y servidores. La mayoría de los virreyes eran nobles en España y contaban con pequeñas «cortes» que los seguían cuando viajaban a Indias.

El entorno doméstico del virrey estaba conformado por el mayordomo mayor, el caballerizo mayor, el maestresala y el camarero, con subordinados como los gentiles hombres, los pajes y los lacayos ${ }^{5}$. Existía también el oficio de capitán de la sala de armas. La protección del virrey estaba a cargo de la llamada Compañía de Gentiles Hombres, Lanzas y Arcabuces.

La cancillería cortesana destacaba por ser un grupo marcado por la grandeza y heterogeneidad y compuesto por el Secretario de la Gobernación y el Secretario de Cámara, además de asesores que ofrecían experiencia y eficacia. La casa del virrey también contaba con ministros encargados del culto divino.

\section{2. La etiqueta y el ceremonial cortesano}

Las disposiciones y reales cédulas acerca de la etiqueta comenzaron a emitirse apenas instaurados los virreinatos de la Nueva España y del Perú.

Fue el virrey Diego Fernández de Córdova, marqués de Guadalcázar (1622-1629), quien mandó elaborar una detallada Relación de los estilos y tratamientos que se debían usar en la Corte limeña con la intencionalidad de convertirse en guía para el siguiente virrey -el conde de Chinchón- en las mencionadas cuestiones protocolarias. El propio devenir histórico lo confirmará como la base para el establecimiento de un rígido ceremonial que apenas sufriría cambios sustanciales.

En 1680 todas las normativas de este tipo se compendian en la Recopilación de Leyes de Indias; conjunto de disposiciones legislativas reunidas y ordenadas en nueve libros que comprendían alrededor de

5 Diccionario de Autoridades. Edición facsímil. 3 vols. Madrid. Gredos. 1979 [1726]: II, 345. 
seis mil cuatrocientas leyes ${ }^{6}$. Publicada durante el reinado de Carlos II, aparecen reunidos en un único cuerpo jurídico retazos legislativos revisados una y otra vez de Carlos I, Felipe II, Felipe III y Felipe IV. Destacamos el Título Quince del Libro III, «De las precedencias, ceremonias y cortesías», el que se encargue de detallar casuísticamente muchos de los aspectos protocolarios objeto de nuestro análisis.

\section{EL RECIBIMIENTO DE LOS VIRREYES}

En el medievo, la entrada real constituía una sólida tradición. El rey era recibido en la ciudad de una forma solemne. Con el Renacimiento el recibimiento real se transformará en entrada triunfal al utilizar el lenguaje formal clásico para ensalzar la figura del rey. El arco será su máxima manifestación como toma de posesión de la ciudad, del gobierno y del reino.

Con el nombramiento del virrey, en la Corte comenzaban los preparativos de viaje, con los trámites necesarios en la Casa de Contratación. El viaje comenzaba desde Sevilla o Sanlúcar de Barrameda hasta Cartagena de Indias; de aquí a Portobelo, Panamá; desde Panamá al puerto de Paita. Ya desde Cartagena o Portobelo se mandaba avisos a las distintas autoridades limeñas notificando su llegada. En Paita se volvía a enviar una carta a la real audiencia, virrey y cabildo de la ciudad de Lima y se decidía acerca de las dos formas de continuar el viaje: por mar o por tierra. El viaje por tierra era más cómodo, pero tenía el inconveniente de ocasionar más gastos en los lugares por donde pasaba y se alojaba el virrey. Por mar era más penoso pero más económico. El cabildo de la ciudad, al tener las primeras noticias del viaje del nuevo mandatario, comenzaba a realizar los preparativos de bienvenida o recibimiento.

\section{III.1. Recibimiento y juramento ${ }^{7}$}

El virrey solía llegar en litera o carroza hasta las inmediaciones del arco triunfal, donde era alcanzado por la guardia de soldados. Se

${ }^{6}$ Recopilación de Leyes de Indias. Recopilación de leyes de los Reynos de las Indias. Edición facsímil. 4 vols. Madrid, Ediciones Cultura Hispánica, 1973 [1681]: II, ff. 63-75. Véase de esta obra el Libro III, título 15: «De las precedencias, ceremonias y cortesías», que se encarga de detallar casuísticamente muchos de los aspectos protocolarios objeto de nuestro análisis.

7 Vargas Ligarte, Rubén, Historia General del Perú, vol. II, pág. 180, nota 1. Horacio Urteaga, El Virrey don Francisco de Toledo, págs. 259-330. La relación fue 
le entregaba un caballo, regalo de la ciudad, y lo montaba hasta el lugar donde debía de hacer el juramento.

En el cortejo se reunían todos los representantes de los distintos estados de la sociedad limeña. Las formas no se podían alterar fácilmente y sin motivos, pues provocaban problemas en cuestiones de orden y preeminencias.

El criterio del orden en el desfile se basa en considerar que, cuanto más cerca del virrey, mayor importancia en el gobierno del reino ${ }^{8}$. Compartía esa posición privilegiada el otro poder del reino, la Real Audiencia, representada por el oidor más antiguo. Algunas veces la casa del virrey y su familia también tenían el privilegio de ocupar el centro de la procesión y al caballerizo mayor del virrey se le permitía ir a la derecha del gobernante si no se contaba con la presencia del secretario de la Gobernación.

La presencia virreinal era anunciada a todos por la música que acompañaba al séquito, tocada por conjuntos de atabales, chirimías y trompetas.

En cuanto al juramento, lo describe Bromley ${ }^{9}$ como acto solemne y de trascendental importancia civil que en el estrado formado junto al arco triunfal debía prestar el nuevo virrey. En ese estrado, cerrado con colgaduras, se colocaba una mesa o bufete, con un crucifijo, un misal y cuatro luces. A este recinto ingresaba la autoridad civil: el virrey, los alcaldes, el regidor más antiguo, o el alguacil mayor de la ciudad, y el escribano o secretario municipal. El juramento abría las puertas de la ciudad al nuevo mandatario. Con esa riqueza y espectacularidad se quería afirmar la autoridad y la imagen del virrey y, en definitiva, la autoridad real en las Indias.

En 1784 la Real Audiencia de Lima reformó el ceremonial de recibimiento de los virreyes de forma que la entrada pública se dilataría hasta dos meses después de vivir el virrey en palacio. Tras la visita de Jorge de Escobedo en 1787 se reformó de nuevo el ceremonial, que

publicada por Luis Torres de Mendoza, Colección de documentos inéditos..., vol. VIII, págs. 212-232. De las págs. 229-232 es la descripción del recibimiento.

8 La entrada de don García Hurtado de Mendoza en L. Torres de Mendoza, O. C., págs. 308-327. La Entrada de Montesclaros por Alonso de Camón, escribano. AMI, Libro 2. ${ }^{\circ}$ de Cédulas y Provisiones reales, ff. 78-79. La relación de la entrada de Guadalcázar fue escrita por el mayordomo del cabildo Antonio Román de Herrera Maldonado, AML, Libro 3. ${ }^{\circ}$ de Cédulas y Provisiones reales, ff.504 y ss. Estas dos últimas publicadas por Bromley en «Recibimientos...», págs. 66-68 y 71-78.

9 Bromley, Juan, Recibimientos de Virreyes en Lima, en Revista Histórica, n. ${ }^{\circ} 20$. Lima. 1953. págs. 5-108. 
se aprobó en 1788, de modo que el juramento se haría en palacio. En 1785 se suprimiría la entrada pública según Cédula Real ${ }^{10}$.

\section{III.2. Recorrido}

Desde Montesclaros, todos los virreyes del siglo vinieron desde el Callao y entraron por el arco, que se levantaba en la última calle de la población hacia su lado occidental. Por lo general, se hacía de listones de madera, cubierto de lienzo pintado de blanco, a imitación de mármol, desarmable para poder utilizarlo en otras oportunidades. En él se pintaban las armas reales, las del virrey que ingresaba y las de la ciudad ${ }^{11}$. En los recibimientos de Nueva España, el viaje de los virreyes se transformaba en un rito que recordaba la conquista del país a sus habitantes y la lealtad debida a la Corona española ${ }^{12}$.

Esta quizás sea la causa por la que las entradas de virreyes se configuran formalmente como verdaderos triunfos, asemejándose a cómo se les honraba por las gestas realizadas a los héroes en la antigua Roma. En los virreinatos americanos se exaltaba al virrey previamente a que hubieran realizado su tarea de gobierno.

Para enaltecer al nuevo gobernador se valían de una iconografía marcada por el paralelismo entre las fábulas de los dioses y héroes de la Antigüedad y los hechos más significativos de la vida del homenajeado y de sus más ilustres antepasados. Los héroes griegos son habituales durante todo el siglo XVII; los grandes dioses del panteón clásico -Marte, Apolo, Júpiter- aparecen concentrados hacia mediados del siglo XVII; a finales de este siglo XVII y durante toda la centuria siguiente se incorporan héroes bíblicos, como Sansón, y personajes históricos, estos últimos siempre referidos a la Antigüedad latina -Julio César, Vespasiano o Maximino-.

\section{III.3. Los gastos del recibimiento}

En España existía la costumbre de que, cuando se recibía a un rey, los gastos se cubrían con las rentas del ayuntamiento. En América, se siguió esta práctica. Con el virrey Mendoza (1551) empieza

10 Bromley, Juan, Recibimientos de Virreyes en Lima, en Revista Histórica, n. 20. Lima. 1953, págs. 14-18.

${ }^{11}$ Bromley, Juan, Recibimientos de Virreyes en Lima, en Revista Histórica, n. ${ }^{\circ} 20$. Lima. 1953, págs. 5-108.

12 Mínguez Cornelles, Víctor. Los Reyes distantes. Universitat Jaume I, 1995, págs. 32-33. 
la costumbre, que pasará a ley, de ser necesaria la autorización de la Real Audiencia para hacer los gastos.

Entre los gastos más importantes se encontraban los referidos al palio y los ropajes de los regidores. El abuso del palio suponía además el abuso de los capitulares para comprarse ropas nuevas y costosas. Las partidas de gastos por las ropas de los cabildantes llegaban a un cuarto y un tercio del presupuesto total.

Ante unos gastos cada vez mayores Felipe III dicta una Cédula, de 31 de mayo de 1600, que limita los gastos a cuatro mil ducados en «cosas útiles y necesarias con intervención de la Audiencia». No obstante, esta ley siguió sin respetarse en los sucesivos recibimientos, como ocurrió con el conde de Monterrey en 1604 y el marqués de Montesclaros en 1607, por lo que, por Cédula del 2 de agosto de 1614, Felipe III autoriza un dispendio de doce mil pesos para las entradas de los virreyes en Lima, teniendo en consideración que las de Monterrey y Montesclaros oscilaron entre los doce mil y los catorce mil pesos ${ }^{13}$.

Las discrepancias normativas aparecen de nuevo con una Real Cédula de 28 de diciembre de 1619, en la que se prohibía el uso de palio a los virreyes. No era nueva, sino que revalidaba la de 1573, que no se había respetado nunca ${ }^{14}$.

Finalmente, en 1639 Felipe IV volvió a autorizar el uso del palio con el nuevo virrey del Perú, marqués de Mancera, y confirmaba los gastos de doce mil pesos en Lima y ocho mil en México.

\section{III.4. El palio}

Se trata de un elemento sacro destinado a cubrir al Santísimo Sacramento en salidas solemnes y públicas. En la península se utilizó por primera vez con motivo de la entrada real en Sevilla de Alfonso XI en 1327. La misión del palio era sacralizar a la persona real. En la península continuaron utilizándose por los monarcas españoles, y se extendió su uso también a los virreyes de la Nueva España y el Perú.

El palio que portaban los regidores desde el arco del juramento hasta la catedral y palacio virreinal solía ser de seis varas de largo y cuatro y dos tercias de ancho, de terciopelo carmesí, con flecos de oro y seda. Sus pies para portarlo eran de cuatro varas de alto, doradas o plateadas, con sus casquillos, e inscritas las armas reales.

13 AML, Libro 5. ${ }^{\circ}$ de Cédulas y Provisiones, f. 22 v., Madrid 2-8-1614.

${ }^{14}$ AML, Libro 5. ${ }^{\circ}$ de Cédulas y Provisiones, f. 184 v. 
Bajo él marchaban los virreyes a caballo, aunque un poco más adelantados del palio para no quedar cubiertos por él, lograr presenciar en su recorrido el concurso de las gentes y corresponder los saludos que se les hacían, y cumplir así el objetivo de poder ver y ser vistos ${ }^{15}$.

Según los cronistas Montesinos y Cobo, el primer virrey del Perú, Blasco Núñez, ya entró bajo palio de brocado $^{16}$, y posteriormente Núñez Vela, el Marqués de Cañete, don Andrés Hurtado de Mendoza, el Conde de Nieva, don Francisco de Toledo, don Martín Enríquez, el Conde del Villar, don García Hurtado de Mendoza, don Luis de Velasco, el Conde de Monterrey, el Marqués de Montesclaros y el Príncipe de Esquilache ${ }^{17}$. Don Antonio de Mendoza (1551) no quiso hacer uso del mismo, si bien se libraron dos mil pesos para las ropas de los regidores y el palio ${ }^{18}$.

Durante el siglo XVIII se siguió utilizando, hasta la reforma de Escobedo, en 1787-88, en que se suprimió.

\section{III.5. El caballo y la carroza}

El caballo era un regalo tradicional desde el medievo, símbolo del mundo medieval, guerrero y conquistador, en la entrada de un rey en un reino o ciudad.

Sobre la silla del caballo se ponía el teliz, cubierta de terciopelo que tapaba al corcel hasta debajo de los estribos. En esa forma sólo la podían usar en el Perú los virreyes, como demostración de grandeza, para el paseo público desde el instante en que prestaba el juramento hasta su llegada a la Catedral, y de esta a su palacio ${ }^{19}$.

Para el recibimiento del marqués de Mancera (1639) parece que el cabildo regaló una carroza al virrey, además de un caballo com-

15 Bromley, Juan, Recibimientos de Virreyes en Lima, en Revista Histórica, XX, pág. 26.

16 Montesinos, Fernando De, Anales del Perú. Edición de Víctor M. Maurtua. Madrid, Imprenta de Gabrile L. y del Horno. vol. 1, págs. 142-143. Cово, BernaBÉ, Historia de la Fundación de Lima, en Obras del padre Bernabé Cobo. 2 vols. Estudio preliminar y edición de Francisco Mateos. Serie Biblioteca de Autores Españoles, vols. 91-92. Madrid, Atla,. págs. 89-90.

17 Bromley, JuAn, Recibimientos de Virreyes en Lima, en Revista Histórica, XX, págs. 24-25.

18 Libros de Cabildos de Lima, Libros de Cabildos de Lima. Descifrados y anotados por Bertram T. Lee y Juan Bromley. 22 vols. Lima, Concejo Provincial de Lima, 19351962, III, págs. 431-432.

19 Bromley, JuAn, Recibimientos de Virreyes en Lima, en Revista Histórica, XX, pág. 22.

(C) UNED. Revista de Derecho UNED, núm. 11, 2012 
prado por cuatrocientos cincuenta pesos ${ }^{20}$. Sería la primera vez que se regalara una carroza, lo que supuso un nuevo gasto que haría aumentar sustancialmente el presupuesto.

\section{III.6. La ropa de los regidores}

Los alcaldes y regidores tenían derecho a que se les diera las telas para las ropas de gala que vestirían durante el desfile del virrey y a que se les pagara la hechura de esos vestidos. Por lo general el color de las ropas era el carmesí -propio de las personas reales y símbolo alegría-, y el género preferido el terciopelo, el raso o el damasco, e iban adornadas con joyas y plumas. Estos trajes quedaban en poder de los regidores pasado el festejo, por lo que a veces eran objeto de abuso y tenían especial interés en que no se omitiera esta partida en el presupuesto.

\section{III.7. Luminarias, fuegos y corridas de toros}

Cuando se tenía noticia cierta de la llegada del nuevo virrey se acudía a celebrarlo de modo inmediato. Así, se hacían luminarias en los balcones de las casas capitulares y desfilaban caballeros con hachas encendidas por las calles y plazas de Lima ${ }^{21}$. Estos espectáculos se contrataban también para la noche del recibimiento o la siguiente. Incluso se le ofrecían al virrey en la chácara donde se hospedaba.

También con el mismo motivo se celebraban en la plaza mayor de Lima cinco corridas o juegos de toros, dos en honor del embajador del nuevo gobernante y tres en honra de este.

El virrey, con los oidores y sus mujeres, presenciaba las fiestas desde las casas del Cabildo. En los arcos de los portales se levantaban tabladillos, unos oficiales y otros para que los ocupasen los particulares mediante pago. En la plaza se armaba una valla para las milicias. Se lidiaban en cada corrida hasta veinte y veinticinco toros encintados. Se utilizaban para la muerte del toro rejones, medias lanzas y espadas anchas. Las llaves de la plaza eran entre-

${ }^{20}$ AML, 1639, ff. 35 y 37 v. El virrey escribió al cabildo diciendo que no hiciera tantos gastos, que él tenía un caballo con el que podría entrar, y ese dinero podría destinarlo a la carroza. El cabildo no aceptó.

${ }^{21}$ Libros de Cabildos de Lima, Libros de Cabildos de Lima. Descifrados y anotados por Bertram T. Lee y Juan Bromley. 22 vols. Lima, Concejo Provincial de Lima, 1935-1962, X, pág. 182. 
gadas comúnmente a los alcaides, que presidían el espectáculo. Aunque había toreros de a pie, pagados, muchos caballeros principales de la ciudad rejoneaban para dar muestra de su bravura y gallardía. Había también toreros bufos. En ocasiones los indios garrocheaban.

El Perú ha mantenido muy viva la afición taurina que llegó con la primera oleada de conquistadores, tanto que una leyenda, desmentida en vano por los historiadores, asegura que don Francisco Pizarro mató a rejonazos el segundo torete de la primera corrida celebrada en el Perú en 1540.

\section{CONCLUSIONES}

En el recibimiento y entrada pública de un nuevo virrey la etiqueta cortesana cobraba su mayor dimensión. Se trataba de un espacio ritual en movimiento en el que la principal finalidad consistía en realzar, con un conjunto de manifestaciones estéticas, la figura del virrey en una doble dimensión: como "alter ego" del monarca y como expresión de su poder en las nuevas tierras. En esencia, se guardaban las mismas características que tenían los desplazamientos por la península del monarca de la Corte Real. La principal de ellas era la centralidad e inaccesibilidad del gobernante, así como realzar la sacralidad de la figura mayestática y convertirse así en reflejo del ordenamiento social. 